\title{
Ductility and Seismic Suitability of Locally Sourced High Yield Rebars in Benin City
}

\author{
Nwankwo E. ${ }^{1, *}$ and Attama E. ${ }^{2}$ \\ ${ }^{1,2}$ Department of Civil Engineering, Faculty of Engineering, University of Benin, Benin City, Edo State, Nigeria \\ Corresponding Author: *nwankwoebuka@yahoo.com
}

https://doi.org/10.36263/nijest.2020.02.0211

\begin{abstract}
Ductility is the ability of a system to sustain large deformations beyond its yield point without breaking or failing. Eurocode 8 makes allowance for receipt of seismic forces using the damping capacity of ductile members. This allows for the absorption of energy and helps increase the amount of energy absorbed by ductile structures before failure. This paper investigates the maximum ductility locally sourced steel rebars in Benin City structure can sustain without damage by establishing parameters that influence ductility. Tensile tests were conducted for rebar sizes of $10 \mathrm{~mm}, 12 \mathrm{~mm}$, and $16 \mathrm{~mm}$ diameters, which were sourced from three different vendors within Benin City, Nigeria. The strain-hardening ratio $S_{t u} / S_{t y}$, i.e. the ratio of tensile strength $S_{t u}$ to yield strength $S_{t y}$, and the elongation at maximum tensile force $A_{g t}$ were investigated in order to determine plastic deformation capacity and the degree of ductility of these rebars. A numerical model - the modified Ramberg- Osgood and Rasmussen equations - was modified in order to predict the experimentally obtained ductility parameters of these locally sourced rebars. The model collaborates well with experiments and could be used to establish ductility parameters of local rebars. Also, ductility test results showed that strain hardening ratios and elongation were relatively low (recommended strain hardening ratio of rebar for seismic design is 1.15) and this could result in reinforced concrete structures made with these rebar exhibiting moderate ductility, i.e. a moderate plastic deformation capacity which might not have sufficient energy absorbing capacity in events of large earthquakes.
\end{abstract}

Keywords: Ductility, Yield, Elongation, Strength, Seismic, Rebars

\subsection{Introduction}

The mechanical strength of steel can be increased by the addition of various alloying elements. However, the trade-off between strength and ductility is an issue in the manufacture of rebars used in reinforced concrete works. To this end, various steel rebars manufactured in various jurisdictions come with varying strengths and ductility properties (Dolega, 1956; Noor and Ahmed, 2008; Panigrahi et al., 2009; Huang and Young, 2012).

Obtaining adequate ductility of steel rebars is extremely important in the seismic design of reinforced concrete design. Thus, it is very important to investigate the ductility characteristics of rebars obtained from different localities. In Europe, for instance, the technological development of reinforcing steel had resulted in rebars with varying ductility. Initially, the development was characterized by the effort to obtain a higher and higher yield strength at the expense of ductility (Bachmann, 1998; Bachmann, 2000).

As regards analytical modelling of stress-strain behaviors of steel, different models have been postulated. Different material models describing this nonlinear behavior of steel have been developed in the last few years. However, the most widely used model was originally proposed by Ramberg and Osgood (Ramberg and Osgood, 1943; Rasmussen, 2003; Real et al., 2014).

Since ductile materials undergo significant cross-sectional reduction due to necking after ultimate tensile strength, true stresses and strains are usually more important than engineering stresses and 
strains in analysing large strain-strain behaviours (Kamaya, 2016; Pranav et al., 2019). However, in this work the engineering strain and stresses of rebars were investigated. It is important to note that engineering stress and strain are important parameters used to obtain true strain and stresses of materials.

The design of steel structures is greatly influenced by ductility. In earthquakes, the acceleration of structural systems, as a result of peak ground accelerations are influenced by their ductility (Kermani et al., 2016). Fundamentally, the seismic design of structures is based on the effects inertia forces on structural systems. The seismic behaviour systems are characterized by their ductility and indeterminacy (Morsali and Behnamfar, 2019; De Matteis et al., 2000).

In this research, ductility properties - in terms of suitability for seismic designs - of locally sourced rebars are determined theoretically and experimentally. There is a paucity of literature to show the suitability of local rebars for seismic design. The Ramberg-Osgood and Rasmussen models were modified in order to predict the ductility properties of locally sourced rebars. Recommendations are made on the suitability of steels sourced from Benin City in seismic designs.

\subsection{Methodology}

The steel bars used for this experiment were sourced in Benin City, Nigeria between January 2018 to December 2018 from 3 main industrial vendors. The various sizes of the steel rebars in terms of diameters- i.e. $10 \mathrm{~mm}, 12 \mathrm{~mm}$ and $16 \mathrm{~mm}$ - were tested in the laboratory for their seismic performance Stress-strain tests were conducted. Figure 1 shows the Avery Universal Testing Machine utilized in this study.

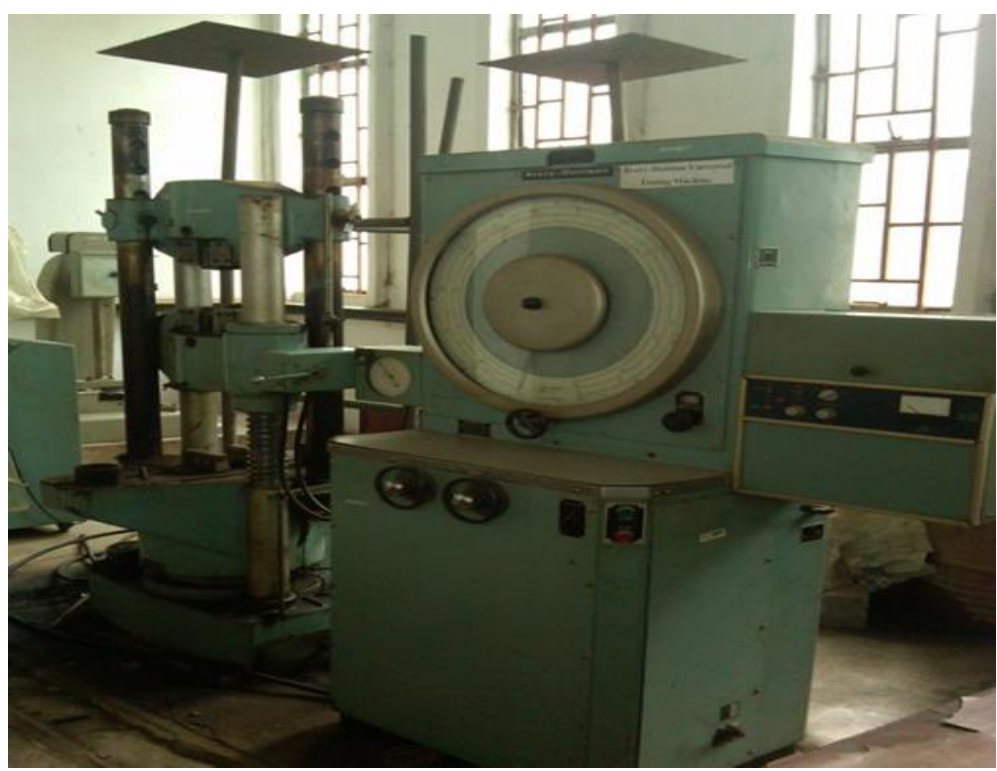

Figure 1: Universal Testing Machine

Tensile test was conducted on various sizes of the steel bar selected. Each steel bar was cut to $500 \mathrm{~mm}$ and tensioned in the Universal Tensile Machine (UTM) at the department of Mechanical Engineering, University of Benin. Tensile tests were conducted according to specifications laid out in ASTM 370. Strengths and strains were manually recorded and computed.

\subsection{Theoretical Background}

A modified Ramberg- Osgood and Rasmussen equations shown in Eq. (1) to (4), where $\sigma$ is stress, $\varepsilon$ is strain, $\varepsilon_{u}$ is strain at ultimate tensile strength, $\varepsilon_{\text {yield }}$ is strain at yield, $E$ is the Young's modulus, $S_{t y}$ is the tensile yield stress of the material, $S_{t u}$ is the ultimate tensile strength of the material, and $n$ and $m$ are the strain hardening exponents, was used in estimating ductility requirements of steel and the associated stress-strain behaviour in this research. 


$$
\begin{aligned}
& \varepsilon=\frac{\sigma}{E}+0.0025\left(\frac{\sigma}{S_{t y}}\right)^{n} \quad \text { for } \sigma<S_{t y} \\
& \varepsilon=\frac{\sigma-S_{t y}}{E}+0.9 \varepsilon_{u}\left(\frac{\sigma-S_{t y}}{S_{t u}-S_{t y}}\right)^{m}+\varepsilon_{y i e l d} \quad \text { for } \sigma>S_{t y} \\
& m=1+0.4 \frac{S_{t y}}{S_{t u}} \\
& \varepsilon_{u}=1-0.9 \frac{S_{t y}}{S_{t u}}
\end{aligned}
$$

In order to obtain true stresses and strains, obtained engineering parameters can be converted using Eq. (5) and (6).

$$
\begin{aligned}
& \sigma_{\text {true }}=\sigma_{\text {nom }}\left(1+\varepsilon_{\text {nom }}\right) \\
& \varepsilon_{\text {true }}=\operatorname{In}\left(1+\varepsilon_{\text {nom }}\right)
\end{aligned}
$$

Where subscript nom and true represents engineering values and true values, respectively.

\subsection{Results and Discussion}

Tables 1 to 3 shows the values of maximum elongation at maximum stress obtained from experiment and from modified Rasmussen-Osgood curve predictions. The tables show test results for samples with diameters between $10 \mathrm{~mm}$ and $16 \mathrm{~mm}$. A total of 72 rebars were tested. The tables show that value of approximate elongations obtained from experiment can be predicted with a high degree of accuracy using modified Ramberg- Osgood and Rasmussen equations, where $E=1.9 \times 10^{5} \mathrm{~N} / \mathrm{mm}^{2}$ and $n=5.88$ for the tested rebars. The value of $E$ was obtained from the stress strain curve perfumed in the laboratory. In this work, this value corresponds to the tangent of the relatively linear section of the stress- strain curve before yield point.

Tables 1 to 4 show that the average strain hardening ratio of 1.1 obtained for the rebars tested is less than the recommended value of 1.15 for rebars used in reinforced concrete structures for medium ductility seismic designs. See (Bachmann, 2000) for recommended minimum values recommended for seismic design. Also, the average maximum elongation at maximum tensile force obtained (i.e. $8.3 \%$ ) is slightly higher that than the recommended value of $6 \%$ for seismic resisting reinforced

\begin{tabular}{|c|c|c|c|c|c|}
\hline $\begin{array}{l}\text { Source of } \\
\text { Steel }\end{array}$ & $\begin{array}{l}\text { Average value of } \\
\text { Yield Strength, } \\
\mathrm{S}_{\mathrm{ty}},\left(\mathrm{N} / \mathrm{mm}^{2}\right)\end{array}$ & $\begin{array}{l}\text { Average value of } \\
\text { Tensile Strength, } \\
\mathrm{S}_{\mathrm{tu}}\left(\mathrm{N} / \mathrm{mm}^{2}\right)\end{array}$ & $\begin{array}{l}\text { Average value of } \\
\text { Experimental Elongation at } \\
\text { max stress, } \varepsilon_{\mathrm{ut}}\end{array}$ & $\begin{array}{l}\text { Average value of } \\
\text { Theoretical Maximum } \\
\text { Elongation at max stress, } \varepsilon_{\text {up }}\end{array}$ & $\mathrm{S}_{\mathrm{tu}} / \mathrm{S}_{\mathrm{ty}}$ \\
\hline Dealer 1 & 440 & 477 & $8.1 \%$ & $7.8 \%$ & 1.1 \\
\hline Dealer 2 & 452 & 497 & $8.3 \%$ & $9 \%$ & 1.1 \\
\hline Dealer 3 & 437 & 475 & $8.2 \%$ & $8 \%$ & 1.1 \\
\hline
\end{tabular}
concrete structures requiring medium ductility. See (Bachmann, 2000) for recommended minimum values recommended for seismic designs.

Table 1: Experimental and Theoretical elongation at maximum ultimate stress for $10 \mathrm{~mm}$ rebars

\begin{tabular}{|l|l|l|l|l|c|}
\hline $\begin{array}{l}\text { Source of } \\
\text { Steel }\end{array}$ & $\begin{array}{l}\text { Average value of } \\
\text { Yield, } \\
\left(\mathrm{N} / \mathrm{mm}^{2}\right)\end{array}$ & $\begin{array}{l}\text { Average value of } \\
\text { Tensile Strength, } \\
\mathrm{S}_{\mathrm{tu}}\left(\mathrm{N} / \mathrm{mm}^{2}\right)\end{array}$ & $\begin{array}{l}\text { Average of value of } \\
\text { Experimental Elongation at } \\
\text { max stress, } \varepsilon_{\mathrm{ut}}\end{array}$ & $\begin{array}{l}\text { Average value } \\
\text { Theoretical } \\
\text { Elongation at max stress, } \varepsilon_{\mathrm{up}}\end{array}$ & $\begin{array}{c}\mathrm{S}_{\mathrm{tu}} / \mathrm{S}_{\mathrm{ty}} \\
\text { Maximum }\end{array}$ \\
\hline Dealer 1 & 438 & 477 & $8.6 \%$ & $8.1 \%$ & 1.1 \\
\hline Dealer 2 & 447 & 487 & $9 \%$ & 8.2 & 1.1 \\
\hline Dealer 3 & 457 & 497 & $8 \%$ & $8 \%$ & 1.1 \\
\hline
\end{tabular}

Table 2: Experimental and Theoretical elongation at maximum ultimate stress for $12 \mathrm{~mm}$ rebars 
Table 3: Experimental and Theoretical elongation at maximum ultimate stress for $16 \mathrm{~mm}$ rebars

\begin{tabular}{|l|l|l|l|l|l|}
\hline $\begin{array}{l}\text { Source of } \\
\text { Steel }\end{array}$ & $\begin{array}{l}\text { Average value of } \\
\text { Yield Strength, } \\
\mathrm{S}_{\mathrm{ty}},\left(\mathrm{N} / \mathrm{mm}^{2}\right)\end{array}$ & $\begin{array}{l}\text { Average value of } \\
\text { Tensile Strength, } \\
\mathrm{S}_{\mathrm{tu}}\left(\mathrm{N} / \mathrm{mm}^{2}\right)\end{array}$ & $\begin{array}{l}\text { Average value of } \\
\text { Experimental } \\
\text { Elongation at max } \\
\text { stress, } \varepsilon_{\mathrm{ut}}\end{array}$ & $\begin{array}{l}\text { Average value of Theoretical } \\
\text { Maximum Elongation at max } \\
\text { stress, } \varepsilon_{\mathrm{up}}\end{array}$ & $\mathrm{S}_{\mathrm{tu}} / \mathrm{S}_{\mathrm{ty}}$ \\
\hline Dealer 1 & 413 & 450 & $8.5 \%$ & 8.2 & 1.1 \\
\hline Dealer 2 & 433 & 467 & $8.9 \%$ & 7.3 & 1.1 \\
\hline Dealer 3 & 423 & 459 & 7.8 & 1.1 \\
\hline
\end{tabular}

Research has shown the ductility properties of reinforcing steel and the ductility of RC structural elements are affected by the values the strain hardening ratio (Kermani et al., 2016). For instance, early tensile fracture is observed in materials with low strain-hardening ratio and amount of elongation at maximum tensile force (Bachmann, 2000).

Also, extending the modified Ramberg- Osgood and Rasmussen model above for the tested rebars, the strains at yield can be obtained. Table 4 shows that the theoretically obtained strains at yield.

Table 4: Experimental and Theoretical elongation at maximum ultimate stress for $16 \mathrm{~mm}$ rebars

\begin{tabular}{|l|l|l|}
\hline Source of Steel & $\begin{array}{l}\text { Average of value of Experimental Elongation at } \\
\text { yield stress, } \varepsilon_{\mathrm{y}}\end{array}$ & $\begin{array}{l}\text { Average value of Theoretical } \\
\text { Elongation at yield stress, } \varepsilon_{\mathrm{y}}\end{array}$ \\
\hline Dealer 1 & $0.35 \%$ & $0.4 \%$ \\
\hline Dealer 2 & $0.35 \%$ & $0.4 \%$ \\
\hline Dealer 3 & $0.38 \%$ & $0.4 \%$ \\
\hline
\end{tabular}

\subsection{Conclusion}

This work establishes the fundamental ductility parameters, such as strain hardening ratios and elongation, of locally sourced steel rebar. These Parameters obtained are also useful for designing reinforced concrete structures subjected to earthquakes, explosions and blasts, i.e. loads from large shock waves and ground forces. The following conclusion can be drawn from this study:

1. The ductility parameters obtained, in terms of strain hardening ratios, show that the locally sourced steel rebars in Benin City fall below recommended values. This implies that sufficient plastic rotations at failure would not be achieved with these rebars during explosions or earthquakes. It is important to note that blast loadings and earthquakes result in large deformations resulting in formation of plastic hinges in structures.

2. Ramberg- Osgood and Rasmussen equations can be modified to predict the yield, ultimate strengths and corresponding strains of rebars. Thus, these equations serve as robust predictive tools for establishing ductility parameters for these rebar

3. A significant amount of plasticity is observed between yield strain and the strain at ultimate tensile stress for the locally sourced rebars tested in this study. However, the corresponding stresses at these points do not increase significantly. This implies that these rebars do not experience strain hardening in their plastic regions.

4. In order to use these tested rebars for designs requiring significant ductility such as earthquake and blast resisting structures, care should be taken in order to ensure that adequate ductility is mobilized by utilized rebars within the reinforced concrete system since their estimated strain hardening ratios and elongation at maximum stress gives moderate values

Fundamentally, plastic design of complex reinforced concrete sections require adequate estimations of strains and stresses in rebars at ultimate limit states. Reinforced concrete structures rely on the ductile capacity of rebars to resist large forces. The ability to predict these values would help the engineer to accurately design reinforced concrete sections from first principles.

\section{References}

ASTM A370. Standard Test Methods and Definitions for Mechanical Testing of Steel Products.

Bachmann, H. (2000). Problems relevant to poor Ductility Properties of European Reinforcing Steel, 12 WCEE 2000: 12th World Conference on Earthquake Engineering; Auckland, New Zeland, Sunday 30 January - Friday 4 February 2000; Vol. 2: Earthquake engineering in practice. Social and economic issues 
Bachmann, H., Dazio, A. and Lestuzzi, P. (1998). Developments in the Seismic Design of Buildings with RC Structural Walls. Proceedings of the 11th European Conference on Earthquake Engineering, September 6-11, CNIT, Paris La Défense, France.

De Matteis, G., Landolfo, R., Dubina, D. and Stratan, A. (2000). Influence of the structural topology on the seismic performance of steel framed buildings. In Moment Resistant Connections of Steel Frames in Seismic Areas. Design and Reability (ed. F.M.Mazzolani), E\&FN Spon, London, 5113-538

Dolega, E. A. (1956). Investigation of Low Alloy, High Strength Steel as a Missile Fuel Tank, Report BLR 53-56, Bell Aircraft, March

EN 1998 Eurocode 8: Eurocode 8: Design of structures for Design of structures for earthquake resistance

Huang, Y. and Young, B. (2012). Material properties of cold-formed lean duplex stainless-steel sections. Thin-Walled Structures, 54, pp. 72-81.

Kamaya, M. (2016). Ramberg-Osgood type stress-strain curve estimation using yield and ultimate strengths for failure assessments. International Journal of Pressure Vessels and Piping, 137, pp. 1-12.

Kermani, H., Behnamfar, F. and Morsali, V. (2016). Seismic Design of Steel Structures Based on Ductility. International Journal of Engineering, 29, pp. 23-30. 10.5829/idosi.ije.2016.29.01a.04.

Morsali, V. and Behnamfar, F. (2019). Seismic damage-based design of steel moment frames. European Journal of Environmental and Civil Engineering, pp. 1-18. 10.1080/19648189.2019.1585963.

Noor, M. A. and Ahmed, A. U. (2008). Study on Grade 75 and 60 Reinforcement in RC Design, BSRM Seminar, pp.-12

Panigrahi, B. K., Srikanth, S. and Sahoo, G. (2009). Effect of Alloying Elements on Tensile Properties, Microstructure and Corrosion Resistance of Reinforcing Bar Steel. J. Mat. Engg. Perform. ASM International, 18, pp.1102-1108.

Pranav, S. P., Rajprasad, A. N., Daniel, K. (2019). An Estimation of Ramberg-Osgood Constants for Materials with and without Luder's Strain Using Yield and Ultimate Strengths, Procedia Structural Integrity, Vol. 17.

Ramberg, W. and Osgood, W. R. (1943). Description of stress-strain curves by three parameters. Technical Note No. 902. Washington, D.C., USA: National Advisory Committee for Aeronautics, 1943.

Rasmussen, K. J. R. (2003). Full-range stress-strain curves for stainless steel alloys. Journal of Constructional Steel Research, 59(1), pp. 47-61.

Real, E., Arrayago, I., Mirambell, E. and Westeel, R. (2014). Comparative study of analytical expressions for the modelling of stainless steel behaviour. Thin-Walled Structures, 83, pp. 2-11.

Cite this article as:

Nwankwo E. and Attama E., 2020. Ductility and Seismic Suitability of Locally Sourced High Yield Rebars in Benin City. Nigerian Journal of Environmental Sciences and Technology, 4(2), pp. 458-462. https://doi.org/10.36263/nijest.2020.02.0211 